\title{
Transcriptome analysis uncovers the key pathways and candidate genes related to the treatment of Echinococcus granulosus protoscoleces with the repurposed drug pyronaridine
}

Yingfang $\mathrm{Yu}^{1 \dagger}$, Jun $\mathrm{Li}^{2 \dagger}$, Weisi Wang ${ }^{1}$, Tian Wang ${ }^{2}$, Wenjing $\mathrm{Qi}^{2}$, Xueting Zheng ${ }^{2}$, Lei Duan ${ }^{1}$, Jiaxu Chen ${ }^{1}$, Shizhu Li ${ }^{1}$, Xiumin $\mathrm{Han}^{3}$, Wenbao Zhang ${ }^{2^{*}}$ and Liping Duan ${ }^{1,3^{*}}$

\begin{abstract}
Background: Cystic echinococcosis (CE) is a life-threatening zoonosis caused by the larval form of Echinococcus granulosus tapeworm. Our previous study showed that an approved drug pyronaridine (PND) is highly effective against $C E$, both in vitro and in an animal model. To identify possible target genes, transcriptome analysis was performed with E. granulosus sensu stricto protoscoleces treated with PND.

Results: A total of 1,321 genes were differentially expressed in protoscoleces treated with PND, including 541 upregulated and 780 downregulated genes. Gene ontology and KEGG analyses revealed that the spliceosome, mitogen-activated protein kinase (MAPK) pathway and ATP-binding cassette (ABC) transporters were the top three enriched pathways. Western blot analysis showed that PND treatment resulted in a dose-dependent increase in protein expression levels of EgMKK1 (MKK3/6-like) and EgMKK2 (MEK1/2-like), two members of MAPK cascades. Interestingly, several heat shock protein (HSP) genes were greatly downregulated including stress-inducible HSPs and their constitutive cognates, and some of them belong to Echinococcus-specific expansion of HSP70.
\end{abstract}

Conclusions: PND has a great impact on the spliceosome, MAPK pathway and ABC transporters, which may underline the mechanisms by which PND kills E. granulosus protoscoleces. In addition, PND downregulates HSPs expression, suggesting a close relationship between the drug and HSPs.

Keywords: Echinococcus granulosus, pyronaridine, RNA sequencing, Protoscoleces, MAPK, Heat shock protein, ABC transporter

\footnotetext{
*Correspondence: wenbaozhang2013@163.com; duanlp@nipd.chinacdc.cn

${ }^{\dagger}$ Yingfang Yu and Jun Li contributed equally to this work.

${ }^{2}$ State Key Laboratory of Pathogenesis, Prevention and Treatment of High Incidence Diseases in Central Asia, Clinical Medical Research Institute, the First Affiliated Hospital of Xinjiang Medical University, 830054 Urumqi, China ${ }^{1} \mathrm{NHC}$ Key Laboratory of Parasite and Vector Biology, WHO Collaborating Centre for Tropical Diseases, National Institute of Parasitic Diseases, Chinese Center for Disease Control and Prevention, 200025 Shanghai, China

Full list of author information is available at the end of the article
}

(c) The Author(s). 2021 Open Access This article is licensed under a Creative Commons Attribution 4.0 International License, which permits use, sharing, adaptation, distribution and reproduction in any medium or format, as long as you give appropriate credit to the original author(s) and the source, provide a link to the Creative Commons licence, and indicate if changes were made. The images or other third party material in this article are included in the article's Creative Commons licence, unless indicated otherwise in a credit line to the material. If material is not included in the article's Creative Commons licence and your intended use is not permitted by statutory regulation or exceeds the permitted use, you will need to obtain permission directly from the copyright holder. To view a copy of this licence, visit http://creativecommons.org/licenses/by/4.0/. The Creative Commons Public Domain Dedication waiver (http://creativecommons.org/publicdomain/zero/1.0/) applies to the data made available in this article, unless otherwise stated in a credit line to the data. 


\section{Background}

Cystic echinococcosis (CE) is a parasitic zoonosis caused by the larval stage of the dog tapeworm Echinococcus granulosus. Chronically infected humans or domestic animals remain asymptomatic for a long time. Infection with E. granulosus leads to the development of one or multiple cysts located mostly in the liver and lungs, which triggers clinical signs in the late stage, including abdominal and chest pain, chronic cough, vomiting, even death $[1,2]$. CE is a globally distributed disease highly endemic in South America, Northern Africa, and Central Asia (especially Western China) [3]. The global health burden of CE is estimated at over 1 million disability-adjusted life-years (DALYs) each year [4]. The disease also affects the local livestock industry's economic benefits, with an estimated yearly loss of at least US\$3 billion [5].

Among current CE treatment options, anti-parasitic drug therapy is widely used for most clinical cases $[6,7]$. Recently, we repurposed an approved anti-malarial drug pyronaridine (PND) as a promising candidate for $\mathrm{CE}$ treatment [8]. Oral administration of PND showed high concentrations of the drug in the liver and lungs, which are the most affected organs in CE. Oral administration, intraperitoneal injection or microinjection procedure (which mimics the clinical percutaneous techniques) significantly reduced the parasite burden in mice. However, the anti-CE mechanism of action of PND is not clear. Previous studies showed that the primary anti-malarial mode of action of PND is inhibition of $\beta$-hematin formation, enhancement of hematin-induced red blood cells lysis, and inducing the formation of abnormal vesicles in the food vacuole of plasmodium $[9,10]$. A transcriptome profiling of Plasmodium falciparum in response to PND reveals a striking abundance of genes encoding hostexported proteins [11]. In addition, PND has been characterized as a potential anticancer agent, which reverses the multi-drug-resistance (MDR) phenotype in MDR cancer cell lines by inhibiting the function of the efflux P-glycoprotein (Pgp) $[12,13]$. In this study, to obtain a comprehensive understanding of the anti-CE mechanism of PND, the global gene expression in E. granulosus protoscoleces (PSCs) following treatment with PND was analyzed using RNA-seq.

\section{Results}

\section{RNA sequencing data analysis}

Global gene expression of PND-treated E. granulosus PSCs was analyzed using an Illumina platform. The obtained sequences were aligned against E. granulosus genome sequences. A total of 60.3 and 58.2 million clean reads were obtained from control and PND groups, respectively (Table 1). The clean reads were mapped to the E. granulosus genome scaffold (https://www.ncbi. nlm.nih.gov/genome/?term=Echinococcus+granulosus)
Table 1 Summary of read mapping results of the sequences generated from E. granulosus PSCs with or without PND treatment

\begin{tabular}{lccl}
\hline Sample & Raw reads & Clean reads & Total mapped \\
\hline Control-1 & $55,872,838$ & $54,440,078$ & $42,085,096(77.31 \%)$ \\
Control-2 & $58,644,988$ & $57,316,610$ & $46,091,104(80.41 \%)$ \\
Control-3 & $70,831,560$ & $69,270,984$ & $51,122,402(73.80 \%)$ \\
PND-1 & $57,226,520$ & $55,803,992$ & $38,687,749(72.07 \%)$ \\
PND-2 & $61,273,444$ & $59,792,756$ & $36,998,770(65.32 \%)$ \\
PND-3 & $60,595,380$ & $58,885,554$ & $33,587,673(60.43 \%)$ \\
\hline
\end{tabular}

reported by Zheng et al. [14]. As shown in a volcano plot (Fig. 1), a total of 1,321 genes were significantly differentially expressed in the PND-treated group compared to the control group, including 541 upregulated and 780 downregulated E. granulosus genes.

\section{Gene ontology (GO) classification}

There were 47 GO terms significantly enriched for differentially expressed genes (DEGs) in PND-treated groups, including 19 biological process terms, 17 cellular component terms, and 11 molecular function terms (Table 2). The most enriched GO terms were associated with cell part, voltage-gated calcium channel complex, binding, voltage-gated calcium channel activity and response to stress.

\section{Biochemical pathway}

The DEGs were also mapped to five KEGG subsystems, including environmental information processing, genetic information processing, organismal systems, metabolism, and cellular processes. The most significantly enriched 10 pathways are shown in Fig. 2. Spliceosome, mitogenactivated protein kinase (MAPK) signaling pathway and ATP-binding cassette $(\mathrm{ABC})$ transporters were the top three significantly enriched pathways (Figs. S1, S2, S3). PND treatment resulted in significant changes in seven $A B C$ transporter genes (Table 3), and three of them (EGR_00511, EGR_00512 and EGR_01347) are involved in MDR, coding MDR transporters and MDR-associated proteins. In addition, we found that PND treatment induced a significant downregulation in a large number of HSP genes including heat shock proteins (HSPs) and heat shock constitutive cognates (HSCs) (Table 4). Most of the genes are of HSP70 family and involved in the top two enriched pathways. HSP70 is a highly expanded gene family in Echinococcus spp. Among the 19 differentially expressed HSP genes, six genes belong to Echinococcus-specific expansion of HSP70 (Table 4).

\section{Validation of key DEGs by qRT-PCR}

To validate the results of transcriptome sequencing, quantitative PCR (qRT-PCR) was used for confirmation 


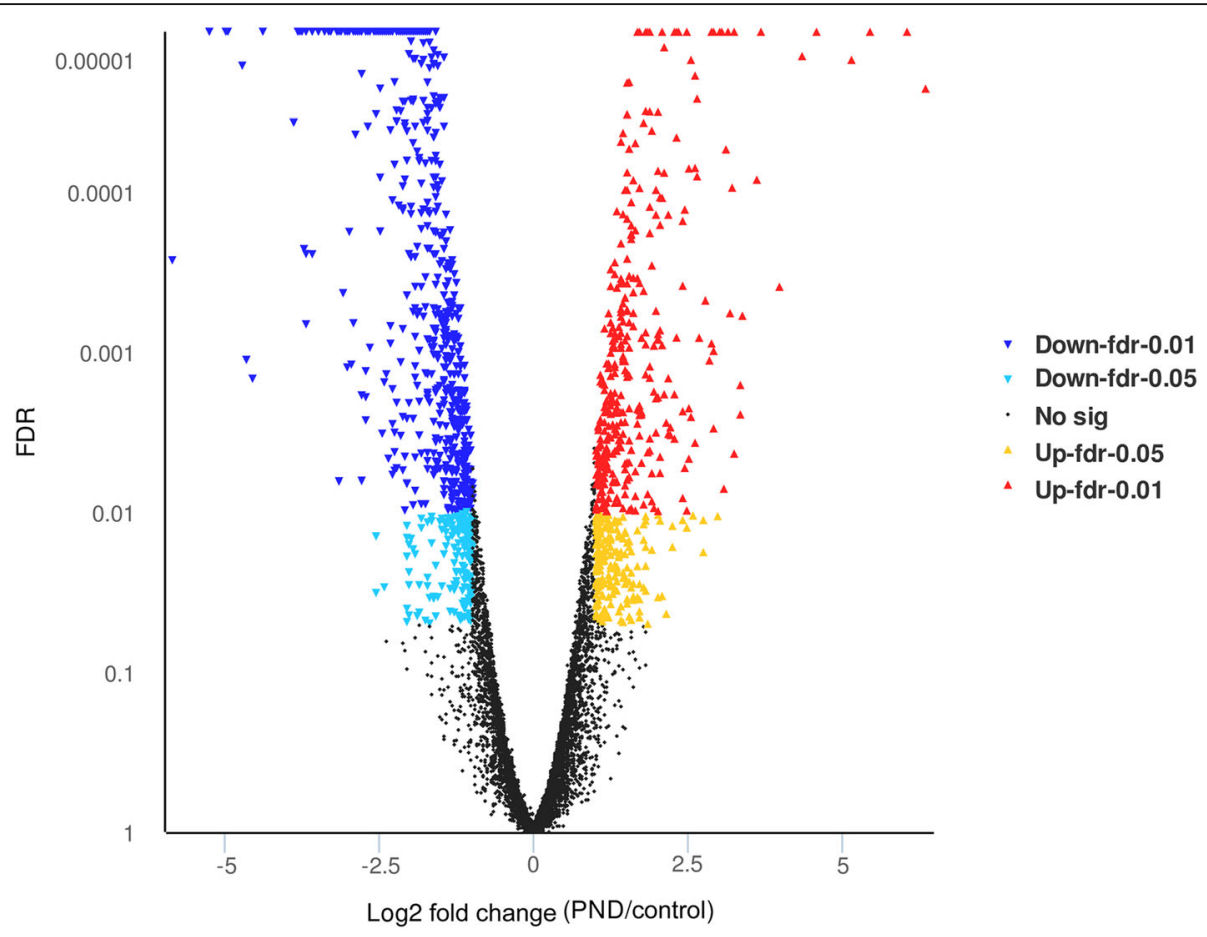

Fig. 1 Volcano plot for the differentially expressed genes (DEGs) between control and pyronaridine (PND)-treated groups. The X-axis shows the differences in gene expression (FDR: adjusted $p$-value), while the Y-axis indicates expression changes (log2 fold change) of the genes in different groups. Splashes were for different genes. Black dots, red and yellow dots, and blue and dark blue dots represent genes with no significant discrepancy, significantly upregulated genes, and significantly downregulated genes, respectively

of eleven representative genes selected from the top three most enriched KEGG pathways, including HSP72, SRF, ECSIT, PKC, MP3K and PTP from the MAPK signaling pathway, SYF, LSM4 and U2AF from spliceosome, and $\mathrm{ABCB} 1$ and $\mathrm{ABCG} 2$ from $\mathrm{ABC}$ transporters (Fig. 3). The qRT-PCR expression patterns of nine out of eleven DEGs were in agreement with the results of the transcriptome analysis, despite the variation of drug concentration or treatment time.

\section{The protein levels of EgMKK1 and EgMKK2}

To further evaluate the changes of key members of MAPK cascades, we determined the protein levels of EgMKK1 (MKK3/6-like) and EgMKK2 (MEK1/2-like) by Western blotting. As shown in Fig. 4, generally, PND treatment upregulated the protein levels of both $E g M K K 1$ and $E g M K K 2$ in a dose-dependent pattern. For $E g \mathrm{MKK} 1$, a significant elevation was observed in PSCs following the treatment of PND at the concentrations of $\mathrm{LC}_{30}$ and $\mathrm{LC}_{50}$ compared with the control group ( $p<$ $0.05)$, while in the case of $E g M K K 2$, it was the treatment of $\mathrm{LC}_{50}(p<0.01)$.

\section{Discussion}

$\mathrm{CE}$ is a neglected disease that has remained "unattractive" to pharmaceutical companies, considering that, in the last few decades, no alternative drugs have been approved for treating it, although some efforts have been made [15-17]. In our previous study, PND, an approved antimalarial drug, was repurposed as an anti-CE candidate. PND killed $100 \%$ of the cysts in a mouse infection model by intraperitoneal injection at $57 \mathrm{mg} / \mathrm{kg} /$ day for three days. When administered orally with a regimen of $57 \mathrm{mg} / \mathrm{kg} /$ day $\times 30$ days, it produced $90.7 \%$ cyst mortality, showing that PND is much more effective than albendazole $(22.2 \%$ cyst mortality at $50 \mathrm{mg} / \mathrm{kg} /$ day), the only anti-CE drug recommended by WHO [8]. However, the anti-parasitic mechanism of PND remains unclear. In this study, RNA-seq technology was used to explore the genes affected by PND on E. granulosus.

Using a suitable low dose, our study showed that PND treatment induced changes in the expression of a large number of genes, including 541 E. granulosus genes upregulated and 780 downregulated, which demonstrates that PND effectively targets $E$. granulosus PSCs. GO enrichment and KEGG analyses revealed that the significantly PND-altered biological processes and pathways were associated with a wide range of cellular components, biological processes, and metabolic pathways, including cellular structures and signaling pathways.

The MAPK cascade is an evolutionarily conserved signal transduction pathway that transmits and converts 
Table $2 \mathrm{GO}$ enrichment analysis of the DEGs of E. granulosus

\begin{tabular}{|c|c|c|c|c|}
\hline Category $^{\mathrm{a}}$ & GO term ID & GO term description & $p$ value & DEG involved \\
\hline \multirow[t]{10}{*}{ Cellular component } & GO:0044464 & Cell part & $2.25 \times 10^{-7}$ & 320 \\
\hline & GO:0044424 & Intracellular part & $2.95 \times 10^{-6}$ & 272 \\
\hline & GO:0005891 & Voltage-gated calcium channel complex & $2.53 \times 10^{-5}$ & 7 \\
\hline & GO:0034704 & Calcium channel complex & $6.26 \times 10^{-5}$ & 7 \\
\hline & GO:0043229 & Intracellular organelle & 0.000177 & 148 \\
\hline & GO:0043226 & Organelle & 0.000224 & 148 \\
\hline & GO:0032991 & Macromolecular complex & 0.000849 & 176 \\
\hline & GO:0016021 & Integral component of membrane & 0.000866 & 135 \\
\hline & GO:0031224 & Intrinsic component of membrane & 0.000876 & 135 \\
\hline & GO:0044425 & Membrane part & 0.0013 & 157 \\
\hline \multirow[t]{10}{*}{ Molecular function } & GO:0005488 & Binding & $8.54 \times 10^{-6}$ & 427 \\
\hline & GO:0005245 & Voltage-gated calcium channel activity & $2.53 \times 10^{-5}$ & 7 \\
\hline & GO:0097159 & Organic cyclic compound binding & 0.000336 & 286 \\
\hline & GO:1,901,363 & Heterocyclic compound binding & 0.000336 & 286 \\
\hline & GO:0004930 & G-protein coupled receptor activity & 0.000512 & 19 \\
\hline & GO:0003676 & Nucleic acid binding & 0.000647 & 169 \\
\hline & GO:0043565 & Sequence-specific DNA binding & 0.000827 & 36 \\
\hline & GO:0043167 & lon binding & 0.000974 & 278 \\
\hline & GO:0043169 & Cation binding & 0.00201 & 158 \\
\hline & GO:0004872 & Receptor activity & 0.00227 & 35 \\
\hline \multirow[t]{10}{*}{ Biological process } & GO:0006950 & Response to stress & $9.19 \times 10^{-6}$ & 39 \\
\hline & GO:0050896 & Response to stimulus & $2.64 \times 10^{-5}$ & 40 \\
\hline & GO:0006355 & Regulation of transcription, DNA-templated & 0.000521 & 85 \\
\hline & GO:0034765 & Regulation of ion transmembrane transport & 0.00192 & 9 \\
\hline & GO:0034762 & Regulation of transmembrane transport & 0.00192 & 9 \\
\hline & GO:0051049 & Regulation of transport & 0.00335 & 10 \\
\hline & GO:0034728 & Nucleosome organization & 0.00396 & 11 \\
\hline & GO:0006334 & Nucleosome assembly & 0.00396 & 11 \\
\hline & GO:0065004 & Protein-DNA complex assembly & 0.00396 & 11 \\
\hline & GO:0071824 & Protein-DNA complex subunit organization & 0.00396 & 11 \\
\hline
\end{tabular}

${ }^{\mathrm{a} T o p} 10$ terms for each category

many extracellular signals by three consecutive phosphorylation events. MAPK pathways are implicated in several cellular processes, including proliferation, differentiation, apoptosis, inflammation, and stress response [18-20]. According to KEGG enrichment analysis, the MAPK pathway comes in second in the top-changed pathways affected by PND. In the last decade, a few components of the MAPK pathway have been identified in E. granulosus, including Egp38, EgERK, EgMKK1 and EgMKK2 [21-23]. Meanwhile, some MAPK inhibitors (e.g., sorafenib, U0126, SB202190) were found to effectively kill $E$. granulosus in vitro and/or in vivo [21, 24, $25]$, proving that the key kinases could be used as potential targets for anti-CE drug development. Following the exposure of PND, a direct effect on the gene levels of the key nodes of the MAPK pathway was not observed. We speculate that, rather than specifically targeting one key node, PND likely had a general impact on the whole pathway, which was demonstrated by the significantly elevated protein levels of EgMKK1 and EgMKK2.

$\mathrm{ABC}$ transporters are transmembrane proteins that actively mediate the translocation of a wide variety of molecules across the cell membrane, including drugs. A subset of $\mathrm{ABC}$ transporters is closely linked to MDR, e.g. the best-characterized multidrug transporter Pgp (ABCB1/MDR1). ABC multidrug transporters have been implicated in drug resistance in several parasites [26, 27]. In the genome of E. granulosus, 22 putative $A B C$ transporters were identified and could be classified into six subfamilies [28]. In this study, PND treatment 


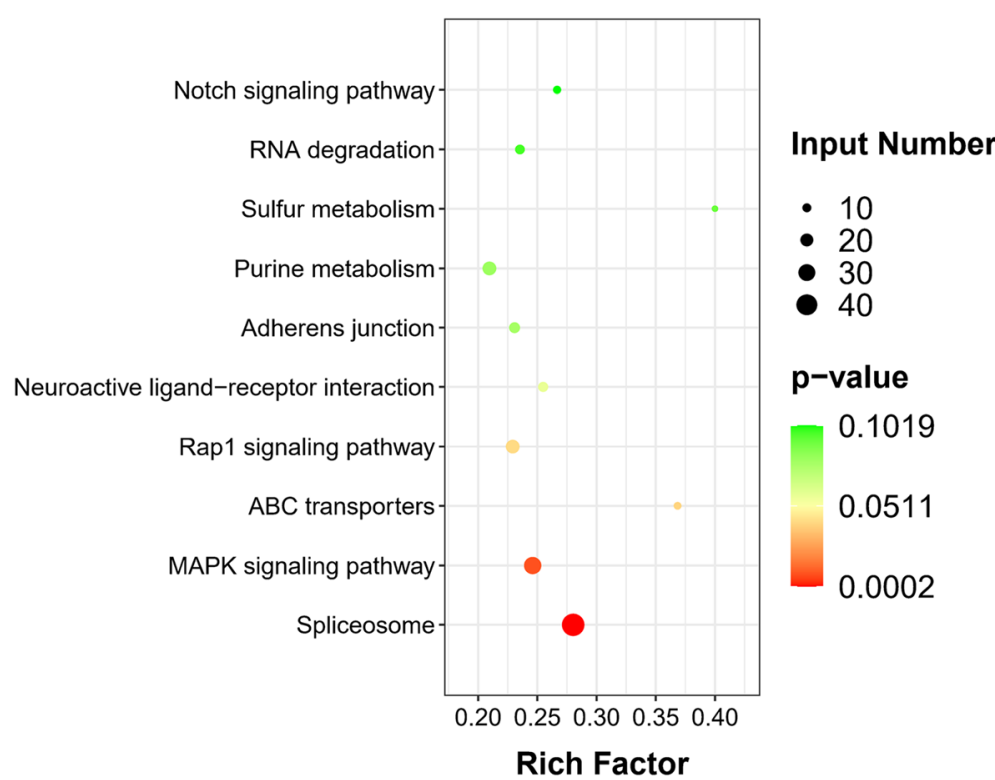

Fig. 2 Scatter plot showing the 10 most enriched KEGG pathways of E. granulosus induced by PND. The Y-axis label represents the distinct KEGG pathways, and the $X$-axis label represents the rich factor. The rich factor refers to the ratio of the DEGs annotated in the pathway versus the total number of genes annotated. Dot size is positively correlated to the number of DEGs. The colors of the dots represent the $p$ values for the enrichment. Red indicates high enrichment, while green indicates low enrichment

induced significant changes in seven $\mathrm{ABC}$ transporter genes (Table 3), and three of them (EGR_00511, EGR 00512 and EGR_01347) are involved in MDR, coding MDR transporters and MDR-associated proteins. Usually, anti-parasitic drug treatment would result in increased/over expression of $\mathrm{ABC}$ transporters, especially MDR transporters, to remove or exclude xenotoxins from cells to guard the normal cellular physiology [2931]. While in this study, after the PND treatment, an ABCB gene (EGR_00511) was significantly downregulated (validated by qRT-PCR, Fig. 3). This indicates that, besides the strong protoscolecidal ability, PND could also negatively regulate the expression of E. granulosus MDR transporter to favor its retention in PSC tissues as an add-on effect. It inspires us that future research efforts could be geared towards the combination of MDR modulators and current anthelmintics to enhance drug susceptibility.
In addition, we found that PND downregulated several HSP genes in E. granulosus PSC. HSPs are originally identified because of their roles in response to heat shock (or other stressors) and these molecules are also molecular chaperones involved in protein folding and maturation [32]. Some HSPs (such as heat shock cognate proteins, HSCs) are constitutively expressed in cells, and serve vital functions in cell metabolism maintenance. We showed that PND treatment induced a significant downregulation in a large number of HSP genes, indicating a close relationship between the drug and HSPs. The differentially expressed HSP genes (Table 4) included five downregulated and three upregulated heat shock proteins and also eleven downregulated constitutive cognates, indicating that not all the DEGs observed in transcriptome analysis were necessarily induced by stress (e.g. an external stimulus caused by PND drug treatment). In addition, most of the HSP genes are of the

Table 3 Differentially expressed ABC transporter genes following the PND treatment

\begin{tabular}{lcll}
\hline Gene ID & Log2 fold change (PND/control) & ABC transporter subfamily & MDR related \\
\hline EGR_07315 & 1.97 & $A B C A$ \\
EGR_07316 & 2.07 & $A B C A$ & $A B C A$ \\
EGR_07314 & 2.03 & $A B C B$ & $\sqrt{ }$ \\
EGR_00512 & 2.10 & $A B C B$ & $\sqrt{ }$ \\
EGR_00511 & -2.27 & $A B C C$ & $\sqrt{ }$ \\
EGR_01347 & 1.23 & $A B C G$ & \\
EGR_02590 & 1.01 & & \\
\hline
\end{tabular}


Table 4 Differentially expressed HSP genes following the PND treatment

\begin{tabular}{|c|c|c|c|c|c|c|}
\hline Gene ID & $\begin{array}{l}\text { Log2 fold change (PND/ } \\
\text { control) }\end{array}$ & $\begin{array}{l}\text { NR_Description } \\
\text { [Echinococcus } \\
\text { granulosus] }\end{array}$ & Spliceosome & $\begin{array}{l}\text { MAPK signaling } \\
\text { pathway }\end{array}$ & $\begin{array}{l}\text { HSP70 } \\
\text { family }\end{array}$ & $\begin{array}{l}\text { Echinococcus- } \\
\text { specific } \\
\text { expansion }\end{array}$ \\
\hline $\begin{array}{l}\text { EGR } \\
04534\end{array}$ & -3.81 & $\begin{array}{l}\text { Heat shock cognate } \\
\text { protein }\end{array}$ & $\checkmark$ & $\checkmark$ & $\checkmark$ & $\checkmark$ \\
\hline $\begin{array}{l}\text { EGR } \\
11004\end{array}$ & -3.29 & $\begin{array}{l}\text { Heat shock cognate } \\
\text { protein }\end{array}$ & $\checkmark$ & $\checkmark$ & $\checkmark$ & \\
\hline $\begin{array}{l}\mathrm{EGR}_{-} \\
06252\end{array}$ & -3.77 & $\begin{array}{l}\text { Heat shock cognate } \\
\text { protein }\end{array}$ & $\checkmark$ & $\checkmark$ & $\checkmark$ & \\
\hline $\begin{array}{l}\text { EGR- } \\
08691\end{array}$ & -4.96 & Heat shock protein 70 & $\checkmark$ & $\checkmark$ & $\checkmark$ & \\
\hline $\begin{array}{l}\text { EGR } \\
10493\end{array}$ & -3.06 & $\begin{array}{l}\text { Heat shock cognate } \\
\text { protein }\end{array}$ & $\checkmark$ & $\checkmark$ & $\checkmark$ & $\checkmark$ \\
\hline $\begin{array}{l}\text { EGR } \\
09649\end{array}$ & -4.73 & $\begin{array}{l}\text { Heat shock cognate } \\
\text { protein }\end{array}$ & $\checkmark$ & $\checkmark$ & $\checkmark$ & $\checkmark$ \\
\hline $\begin{array}{l}\text { EGR } \\
10437\end{array}$ & -2.8 & $\begin{array}{l}\text { Heat shock cognate } \\
\text { protein }\end{array}$ & $\checkmark$ & $\checkmark$ & $\checkmark$ & \\
\hline $\begin{array}{l}\mathrm{EGR}_{-} \\
09650\end{array}$ & -3.88 & $\begin{array}{l}\text { Heat shock cognate } \\
\text { protein }\end{array}$ & $\checkmark$ & $\checkmark$ & $\checkmark$ & \\
\hline $\begin{array}{l}\mathrm{EGR}_{-} \\
10562\end{array}$ & 2.45 & Heat shock protein & & & $\checkmark$ & \\
\hline $\begin{array}{l}\text { EGR } \\
11188\end{array}$ & -5.86 & Heat shock protein 70 & $\checkmark$ & $\checkmark$ & $\checkmark$ & $\checkmark$ \\
\hline $\begin{array}{l}\mathrm{EGR} \\
03078\end{array}$ & 1.75 & $\begin{array}{l}\text { Small heat shock protein } \\
\text { p36 }\end{array}$ & & & & \\
\hline $\begin{array}{l}\text { EGR } \\
04903\end{array}$ & -1.47 & $\begin{array}{l}\text { Heat shock cognate } \\
\text { protein }\end{array}$ & $\checkmark$ & $\checkmark$ & $\checkmark$ & \\
\hline $\begin{array}{l}\mathrm{EGR}_{-} \\
03136\end{array}$ & -1.45 & Heat shock protein & & & & \\
\hline $\begin{array}{l}\text { EGR } \\
09244\end{array}$ & -2.31 & $\begin{array}{l}\text { Heat shock cognate } \\
\text { protein }\end{array}$ & $\checkmark$ & $\checkmark$ & $\checkmark$ & $\checkmark$ \\
\hline $\begin{array}{l}\text { EGR } \\
00589\end{array}$ & -2.71 & $\begin{array}{l}\text { Heat shock protein beta- } \\
11\end{array}$ & & & & \\
\hline $\begin{array}{l}\mathrm{EGR}_{-} \\
07753\end{array}$ & -2.1 & $\begin{array}{l}\text { Heat shock cognate } \\
\text { protein }\end{array}$ & $\checkmark$ & $\checkmark$ & $\checkmark$ & \\
\hline $\begin{array}{l}\mathrm{EGR} \\
05222\end{array}$ & 1.93 & Heat shock protein 70 & $\checkmark$ & $\checkmark$ & $\checkmark$ & $\checkmark$ \\
\hline $\begin{array}{l}\mathrm{EGR}_{-} \\
07332\end{array}$ & -1.33 & $\begin{array}{l}\text { Heat shock cognate } \\
\text { protein }\end{array}$ & $\checkmark$ & $\checkmark$ & $\checkmark$ & \\
\hline $\begin{array}{l}\mathrm{EGR}_{-} \\
09751\end{array}$ & -1.03 & $\begin{array}{l}\text { Heat shock } 10 \text { kda protein } \\
1\end{array}$ & & & & \\
\hline
\end{tabular}

HSP70 family. HSP70 is a highly expanded gene family in E. granulosus [14, 33], and it has been found that some HSP70s may be non-functional transcribed pseudogenes [34]. Through orthology search, six differentially expressed HSP genes were identified to belong to Echinococcus-specific expansion of HSP70 (Table 4). HSPs are implicated in the cause and progression of various diseases, such as infections [35], cancer [36, 37], and neurodegeneration $[38,39]$. In parasites, such as Plasmodium spp. [40], Leishmania spp. [41], and Trypanosoma spp. [42], HSPs have been investigated as potential drug targets. Some of the HSP genes have already been identified and studied in E. granulosus [43, 44]. The results here reported motivate us to study the relationships of PND and HSPs further.

\section{Conclusions}

In this study, the transcriptome landscape of E. granulosus PSCs treated with PND was characterized. This allowed the identification of 1,321 DEGs, some of which were found to exhibit great influence on various life processes of E. granulosus, including MAPK pathway, ABC transporters and HSPs. These findings provide valuable genetic data to facilitate future studies toward understanding the anti-parasitic mechanism of PND. 


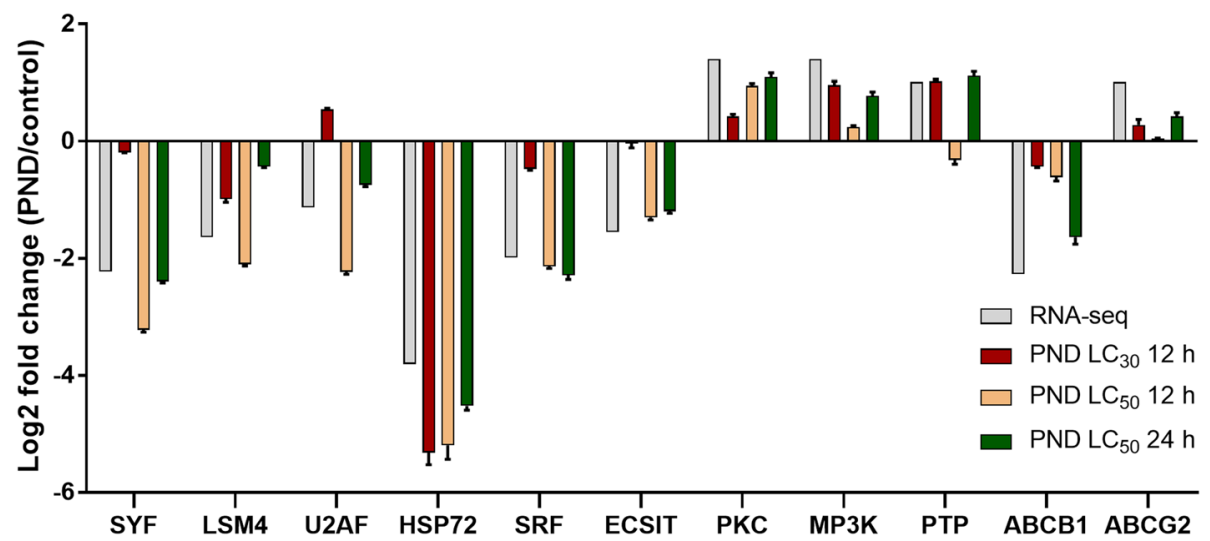

Fig. 3 Verification of the RNA-seq data by qRT-PCR. Bars represent the mean fold changes in the expression of eleven genes in E. granulosus PSCS treated with PND at the concentrations of $L_{30}(30.6 \mu \mathrm{M})$ or $L C_{50}(49.0 \mu \mathrm{M})$ for 12 or $24 \mathrm{~h}$ compared with non-treated PSCs. PSCs used for RNAseq were treated with PND at the concentration of $\mathrm{LC}_{50}(49.0 \mu \mathrm{M})$ for $24 \mathrm{~h}$

\section{Methods}

\section{Drug treatment of E. granulosus PSCs}

E. granulosus sensu stricto PSCs were aspirated from echinococcal cysts of naturally infected sheep livers collected from a slaughterhouse in Urumqi, China [15]. PSCs were treated with $1 \%$ pepsin in saline at $37{ }^{\circ} \mathrm{C}$ for $30 \mathrm{~min}$, with the $\mathrm{pH}$ adjusted to 3.0. After three washes with PBS, the PSCs were cultured in RPMI 1640 culture medium (Gibco, cat\#31,800,022) containing $10 \%$ fetal bovine serum (Gibco, cat\#10,099,141 C) and antibiotics (100 U/mL penicillin and $100 \mu \mathrm{g} / \mathrm{mL}$ streptomycin, Gibco, cat\#15140-122) in a $\mathrm{CO}_{2}$ (5\%) incubator at $37{ }^{\circ} \mathrm{C}$. PND tetraphosphate was synthesized in-house [8] and dissolved in PBS to prepare a drug solution. Viable PSCs were aliquoted in a 24-well plate with each wellcontaining 2,100 PSCs. The wells were randomly divided into two groups. For RNA-seq, the PND group was treated with a PND solution at a final concentration of $49.0 \mu \mathrm{M}\left(\mathrm{LC}_{50}\right)$, and the control group received an equal volume of PBS. Each group included three biological replicates. After incubation for $24 \mathrm{~h}$, the treated and control PSCs were washed with PBS and frozen in liquid nitrogen quickly, then stored at $-80{ }^{\circ} \mathrm{C}$. For qRT-PCR and western blot analyses, the PSCs were treated with $\mathrm{PND}$ at the final drug concentrations of $49.0 \mu \mathrm{M}\left(\mathrm{LC}_{50}\right)$, $30.6 \mu \mathrm{M}\left(\mathrm{LC}_{30}\right)$ or $9.9 \mu \mathrm{M}\left(\mathrm{LC}_{10}\right)$ for 12 or $24 \mathrm{~h}$.

\section{RNA extraction and cDNA library construction}

Total RNA $(5 \mu \mathrm{g})$ extracted from each sample using TRIzol $^{\odot}$ Reagent (Invitrogen, cat $\left.\# 15,596,026\right)$ at $4{ }^{\circ} \mathrm{C}$ was used for RNA-seq analysis. Then, RNA quality was further assessed by the Agilent 2100 Bioanalyser (Agilent Technologies, Santa Clara, CA, USA) and quantified using the NanoDrop spectrophotometer (ND-2000, NanoDrop Technologies). Adapter-modified fragments were selected using gel purification and PCR amplified to create the final cDNA library prepared following the TruSeq $^{\mathrm{Tm}}$ RNA sample preparation Kit from Illumina HiSeq 4000 (Illumina, San Diego, CA, USA). The Illumina HiSeqxten sequenced the paired-end RNA-seq sequencing library $(2 \times 150$ bp read length, San Diego, CA, USA).

\section{RNA-seq bioinformatics analysis}

The raw reads were subjected to adapter trimming and low-quality filtering using SeqPrep (https://github.com/ jstjohn/SeqPrep) and Sickle (https://github.com/najoshi/ sickle) with default parameters. The high-quality clean reads were aligned to the reference genome using the HIASAT (https://ccb.jhu.edu/software/hisat2/index. shtml) software. The DEGs between control and PNDtreated PSCs were identified based on fragments per kilobases per million reads (FPKM) using the Transcripts Per Million reads (TPM) method. DESeq2 (http:// bioconductor.org/packages/stats/bioc/DESeq2/) was used to identify differential expression analysis. Gene expression with $\log 2$ fold change $\geq 1$ or $\leq-1$, and differences in expression with an adjusted $p$-value $<0.05$ were considered to be significant. In addition, the GO and KEGG databases were explored to identify which DEGs were significantly enriched in GO terms and KEGG pathways. GO functional enrichment was carried out by Goatools (https://github.com/tanghaibao/Goatools) [45].

\section{qRT-PCR assay}

Eleven representative genes (four upregulated genes: PKC, MP3K, PTP and ABCG2; nine downregulated genes: HSP72, ECSIT, SRF, SYF, LSM4, U2AF, and $\mathrm{ABCB} 1)$ were selected from the top three enriched pathways, and their gene expression levels in the control and PND-treated groups were evaluated. GAPDH was used as an endogenous control. Gene expression was 

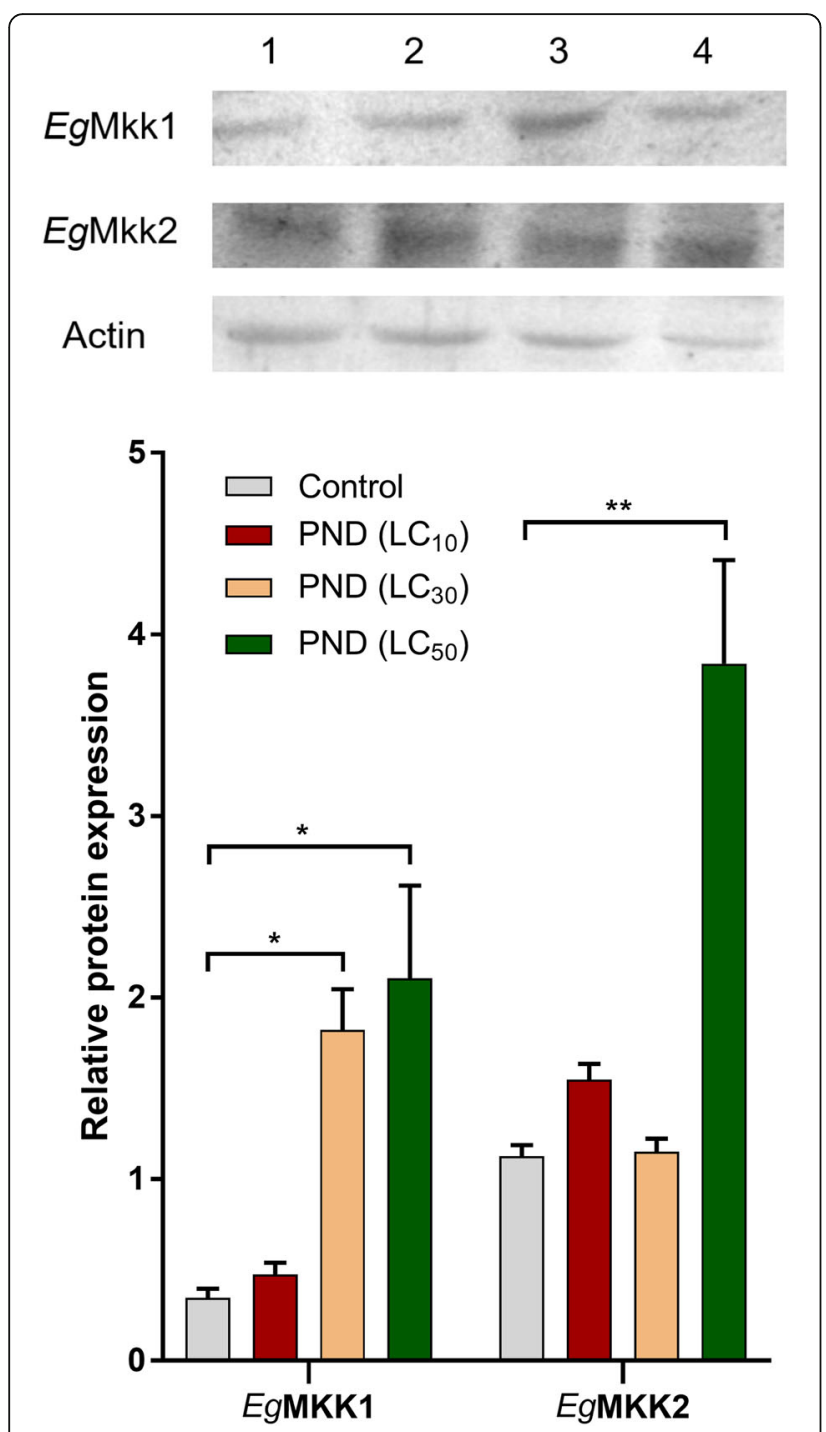

Fig. 4 Western blot analysis of the effect of PND on EgMKK1 and EgMKK2. Protein expression levels of EgMKK1 and EgMKK2 in PSCs without (control, lane 1) or with the treatment of PND at the concentrations of $\mathrm{LC}_{10}(9.9 \mu \mathrm{M}$, lane 2$), \mathrm{LC}_{30}(30.6 \mu \mathrm{M}$, lane 3$)$ and $\mathrm{LC}_{50}(49.0 \mu \mathrm{M}$, lane 4, identical treatment to that of RNA-seq samples) for 24 h. ${ }^{*} p<0.05,{ }^{* *} p<0.01$, compared to control

quantified with SYBR Green Master (Takara, cat\#RR820A, Dalian, China). The primers are shown in Table S1.

\section{Western blot analysis}

The rabbit anti-EgMKK1/anti-EgMKK2 serums are generous gifts from Dr. Chuanshan Zhang, the First Affiliated Hospital of Xinjiang Medical University. Western blot analyses of EgMKK1 and EgMKK2 were performed as previously described [21]. $\beta$-Actin served as a loading control.

\section{Abbreviations}

ABC: ATP-binding cassette; CE: Cystic echinococcosis; DEGs: Differentially expressed genes; HSPs: Heat shock proteins; KEGG: Kyoto encyclopedia of genes and genomes; GO: Gene ontology; MAPK: Mitogen-activated protein kinase; MDR: Multi-drug-resistance; PND: Pyronaridine; PSCs: Protoscoleces; qPCR: Quantitative PCR; RNA-seq: RNA sequencing

\section{Supplementary Information}

The online version contains supplementary material available at https://doi. org/10.1186/s12864-021-07875-w.

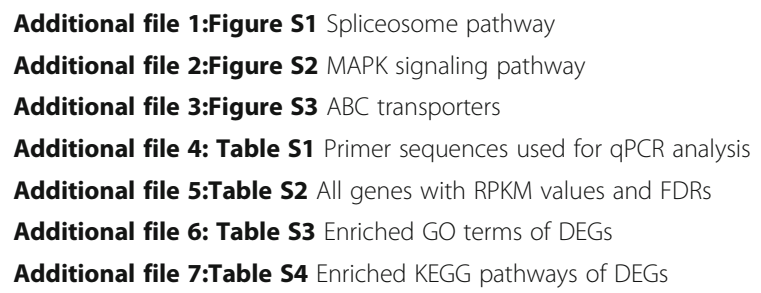

We appreciate the generous gift of the EgMKK1/EgMKK2 anti-serums provided by Dr. Chuanshan Zhang.

\section{Authors' contributions}

$Y Y, J L, W Z$ and LPD designed and coordinated the project. WW, JC and XH synthesized and identified the compounds. JL, TW, WQ and XZ carried out the drug treatment experiments and prepared the samples. YY, WW, LD and $S L$ analyzed and interpreted the transcriptome data. YY, JL and WW wrote the manuscript. WZ and LPD reviewed and revised the drafts of the manuscript. All authors have read and approved the manuscript.

\section{Funding}

This study received financial support from the National Natural Science Foundation of China (32072886 and U1803282), and Clinical Research Project of Healthcare Industry of Shanghai Municipal Health Commission (202040054), and International Cooperation Project of Qinghai Science and Technology Department (2019-HZ-803).

\section{Availability of data and materials}

The RNA-seq data obtained in this study were deposited in the National Center for Biotechnology Information (NCBI) Sequence Read Archive (SRA) database (https://www.ncbi.nlm.nih.gov/sra) under accession number of PRJNA667188.

\section{Declarations}

Ethics approval and consent to participate Not applicable.

\section{Consent for publication}

Not applicable.

\section{Competing interests}

The authors declare that they have no competing interests.

\section{Author details}

${ }^{1} \mathrm{NHC}$ Key Laboratory of Parasite and Vector Biology, WHO Collaborating Centre for Tropical Diseases, National Institute of Parasitic Diseases, Chinese Center for Disease Control and Prevention, 200025 Shanghai, China. ${ }^{2}$ State Key Laboratory of Pathogenesis, Prevention and Treatment of High Incidence Diseases in Central Asia, Clinical Medical Research Institute, the First Affiliated Hospital of Xinjiang Medical University, 830054 Urumqi, China. ${ }^{3}$ Qinghai Provincial People's Hospital, 810007 Xining, China. 
Received: 25 November 2020 Accepted: 1 July 2021

Published online: 13 July 2021

\section{References}

1. Agudelo Higuita NI, Brunetti E, McCloskey C. Cystic echinococcosis. J Clin Microbiol. 2016;54(3):518-23.

2. Ammann RW, Eckert J. Cestodes. Echinococcus Gastroenterol Clin North Am. 1996;25(3):655-89.

3. Craig PS, MCManus DP, Lightowlers MW, Chabalgoity JA, Garcia HH, Gavidia CM, Gilman RH, Gonzalez AE, Lorca M, Naquira C, Nieto A, Schantz PM. Prevention and control of cystic echinococcosis. Lancet Infect Dis. 2007;7(6):385-94.

4. Budke CM, Deplazes P, Torgerson PR. Global socioeconomic impact of cystic echinococcosis. Emerg Infect Dis. 2006;12(2):296-303.

5. Torgerson PR. One world health: socioeconomic burden and parasitic disease control priorities. Vet Parasitol. 2013;195(3-4):223-32.

6. Kern P. Clinical features and treatment of alveolar echinococcosis. Curr Opin Infect Dis. 2010;23(5):505-12.

7. Wen H, Vuitton L, Tuxun T, Li J, Vuitton DA, Zhang W, McManus DP. Echinococcosis: Advances in the 21st Century. Clin Microbiol Rev. 2019;32(2):e00075-18.

8. Li J, Wang W, Yao J, Wang T, Li S, Qi W, Han S, Ren Y, Dang Z, Han X, Guo G, Guo B, Wang L, Duan L, Zhang W. Old drug repurposing for neglected disease: Pyronaridine as a promising candidate for the treatment of Echinococcus granulosus infections. EBioMedicine. 2020;54:102711.

9. Auparakkitanon S, Chapoomram S, Kuaha K, Chirachariyavej T, Wilairat P. Targeting of hematin by the antimalarial pyronaridine. Antimicrob Agents Chemother. 2006;50(6):2197-200

10. Kawai S, Kano S, Chang C, Suzuki M. The effects of pyronaridine on the morphology of Plasmodium falciparum in Aotus trivirgatus. Am J Trop Med Hyg. 1996:55(2):223-29.

11. Kritsiriwuthinan $K$, Chaotheing $S$, Shaw PJ, Wongsombat $C$, Chavalitshewinkoon-Petmitr P, Kamchonwongpaisan S. Global gene expression profiling of Plasmodium falciparum in response to the antimalarial drug pyronaridine. Malar J. 2011;10:242.

12. Qi J, Yang CZ, Wang CY, Wang SB, Yang M, Wang JH. Function and mechanism of pyronaridine: a new inhibitor of P-glycoprotein-mediated multidrug resistance. Acta pharmacologica Sinica. 2002;23(6):544-50.

13. Qi J, Wang S, Liu G, Peng H, Wang J, Zhu Z, Yang C. Pyronaridine, a novel modulator of P-glycoprotein-mediated multidrug resistance in tumor cells in vitro and in vivo. Biochem Biophys Res Commun. 2004;319(4):1124-31.

14. Zheng H, Zhang W, Zhang L, Zhang Z, Li J, Lu G, Zhu Y, Wang Y, Huang Y, Liu J. The genome of the hydatid tapeworm Echinococcus granulosus. Nat Genet. 2013;45(10):1168-75.

15. Wang W, Li J, Yao J, Wang T, Li S, Zheng X, Duan L, Zhang W. In vitro and in vivo efficacies of novel carbazole aminoalcohols in the treatment of cystic echinococcosis. J Antimicrob Chemother. 2017;72(11):3122-30.

16. Loos JA, Dávila VA, Rodrígues CR, Petrigh R, Zoppi JA, Crocenzi FA, Cumino AC. Metformin exhibits preventive and therapeutic efficacy against experimental cystic echinococcosis. PLoS Negl Trop Dis. 2017;11(2):e0005370.

17. Pensel PE, Elissondo N, Gambino G, Gamboa GU, Benoit JP, Elissondo MC. Experimental cystic echinococcosis therapy: In vitro and in vivo combined 5fluorouracil/albendazole treatment. Vet Parasitol. 2017;245:62-70.

18. Yuan J, Dong X, Yap J, Hu J. The MAPK and AMPK signalings: interplay and implication in targeted cancer therapy. J Hematol Oncol. 2020;13(1):113.

19. Lawan A, Bennett AM. Mitogen-activated protein kinase regulation in hepatic metabolism. Trends Endocrinol Metab. 2017;28(12):868-78.

20. Khorasanizadeh M, Eskian M, Gelfand EW, Rezaei N. Mitogen-activated protein kinases as therapeutic targets for asthma. Pharmacol Ther. 2017;174:112-26.

21. Zhang C, Li J, Aji T, Li L, Bi X, Yang N, Li Z, Wang H, Mao R, Lü G, Shao Y, Vuitton DA, Wen $H$, Lin R. Identification of functional MKK3/6 and MEK1/2 homologs from Echinococcus granulosus and investigation of protoscolecidal activity of mitogen-activated protein kinase signaling pathway inhibitors in vitro and in vivo. Antimicrob Agents Chemother. 2019;63(1):e01043-18.

22. Li J, Zhang C, Lü G, Wang J, Wen H, Yan G, Wei X, Lin R. Molecular characterization of a signal-regulated kinase homolog from Echinococcus granulosus. Chin Med J (Engl). 2011;124(18):2838-44.

23. Lü G, Li J, Zhang C, Li L, Bi X, Li C, Fan J, Lu X, Vuitton DA, Wen H, Lin R. Molecular cloning and characterization of a p38-like mitogen-activated protein kinase from Echinococcus granulosus. Korean J Parasitol. 2016;54(6):759-68.

24. Lv H, Li S, Zhang J, Hailong Lv S, Li J, Zhang, Liang W, Mu X, Jiang Y. In vitro effects of SB202190 on Echinococcus granulosus. Korean J Parasitol. 2013; 51(2):255-8.
25. Gelmedin V, Caballero-Gamiz R, Brehm K. Characterization and inhibition of a p38-like mitogen-activated protein kinase (MAPK) from Echinococcus multilocularis: antiparasitic activities of p38 MAPK inhibitors. Biochem Pharmacol. 2008;76(9):1068-81.

26. Greenberg RM. ABC multidrug transporters in schistosomes and other parasitic flatworms. Parasitol Int. 2013;62(6):647-53.

27. Leprohon $P$, Légaré $D$, Ouellette $M . A B C$ transporters involved in drug resistance in human parasites. Essays Biochem. 2011;50(1):121-44.

28. Caña-Bozada V, Morales-Serna FN, García-Gasca A, Llera-Herrera R, Fajer-Ávila EJ. Genome-wide identification of ABC transporters in monogeneans. Mol Biochem Parasitol. 2019;234:111234.

29. Nicolao MC, Denegri GM, Cárcamo JG, Cumino AC. P-glycoprotein expression and pharmacological modulation in larval stages of Echinococcus granulosus. Parasitol Int. 2014;63(1):1-8.

30. James $C E$, Davey MW. Increased expression of $A B C$ transport proteins is associated with ivermectin resistance in the model nematode Caenorhabditis elegans. Int J Parasitol. 2009;39(2):213-20.

31. Kumkate $S$, Chunchob S, Janvilisri T. Expression of ATP-binding cassette multidrug transporters in the giant liver fluke Fasciola gigantica and their possible involvement in the transport of bile salts and anthelmintics. Mol Cell Biochem. 2008;317(1-2):77-84.

32. Shrestha $\mathrm{L}$, Bolaender A, Patel HJ, Taldone T. Heat shock protein (HSP) drug discovery and development: Targeting heat shock proteins in disease. Curr Top Med Chem. 2016;16(25):2753-64.

33. Tsai IJ, Zarowiecki M, Holroyd N, Garciarrubio A, Sánchez-Flores A, Brooks KL, Tracey A, Bobes RJ, Fragoso G, Sciutto E. The genomes of four tapeworm species reveal adaptations to parasitism. Nature. 2013;496(7443):57-63.

34. Koziol U, Iriarte A, Castillo E, Soto J, Bello G, Cajarville A, Roche L, Marín M. Characterization of a putative hsp70 pseudogene transcribed in protoscoleces and adult worms of Echinococcus granulosus. Gene. 2009;443(1-2):1-11.

35. Rochani AK, Singh M, Tatu U. Heat shock protein 90 inhibitors as broad spectrum anti-infectives. Curr Pharm Des. 2013;19(3):377-86.

36. Miyata $Y$, Nakamoto $H$, Neckers L. The therapeutic target Hsp90 and cancer hallmarks. Curr Pharm Des. 2013;19(3):347-65.

37. Mahalingam D, Swords R, Carew JS, Nawrocki ST, Bhalla K, Giles FJ. Targeting HSP90 for cancer therapy. Br J Cancer. 2009;100(10):1523-9.

38. Paul S, Mahanta S. Association of heat-shock proteins in various neurodegenerative disorders: is it a master key to open the therapeutic door? Mol Cell Biochem. 2014;386(1-2):45-61.

39. Adachi H, Katsuno M, Waza M, Minamiyama M, Tanaka F, Sobue G. Heat shock proteins in neurodegenerative diseases: pathogenic roles and therapeutic implications. Int J Hyperthermia. 2009;25(8):647-54.

40. Day J, Passecker A, Beck HP, Vakonakis I. The Plasmodium falciparum Hsp70$x$ chaperone assists the heat stress response of the malaria parasite. FASEB J. 2019;33(12):14611-24.

41. Das S, Banerjee A, Kamran M, Ejazi SA, Asad M, Ali N, Chakrabarti S. A chemical inhibitor of heat shock protein 78 (HSP78) from Leishmania donovani represents a potential antileishmanial drug candidate. J Bio Chem. 2020;295(29):9934-47.

42. Pizarro JC, Hills T, Senisterra G, Pizarro JC, Hills T, Senisterra G, Wernimont AK, Mackenzie C, Norcross NR, Ferguson MAJ, Wyatt PG, Gilbert IH, Hui R. Exploring the Trypanosoma brucei Hsp83 potential as a target for structure guided drug design. PLoS Negl Trop Dis. 2013;7(10):e2492.

43. Pan D, Das S, Bera AK, Bandyopadhyay S, De S, Rana T, Das SK, Suryanaryana W, Deb J, Bhattacharya D. Molecular and biochemical mining of heat-shock and 14-3-3 proteins in drug-induced protoscolices of Echinococcus granulosus and the detection of a candidate gene for anthelmintic resistance. J Helminthol. 2011;85(2):196-203.

44. Ortona $E$, Margutti $P$, Delunardo $F$, Vaccari $S$, Riganò $R$, Profumo E, Buttari $B$, Teggi A, Siracusano A. Molecular and immunological characterization of the C-terminal region of a new Echinococcus granulosus Heat Shock Protein 70. Parasite Immunol. 2003;25(3):119-26.

45. Klopfenstein DV, Zhang L, Pedersen BS, Ramírez F, Vesztrocy AW, Naldi A, Mungall CJ, Yunes JM, Botvinnik O, Weigel M, Dampier W, Dessimoz C, Flick P, Tang H. GOATOOLS: A python library for gene ontology analyses. Sci Rep. 2018;8(1):10872.

\section{Publisher's Note}

Springer Nature remains neutral with regard to jurisdictional claims in published maps and institutional affiliations. 